\title{
Year Two, Setting Up the Right Path: 3D Printing for Low Expense College Courses
}

\section{Hector Erick Lugo Nevarez, University of Texas, El Paso}

Mr. Hector Lugo works as a Student Technology Success Coordinator at The University of Texas at El Paso. He holds a B.S. in Electrical Engineering. He is currently enrolled as a Master of Science with a Major in Electrical Engineering. His motivation and passion pushes him into research in wireless communication, especially in Bluetooth Low Energy and Near Field Communication as well as building projects and fostering innovation with faculty and staff members. As part of the Learning Environments division, the idea to develop, oversee and assess engaging students to expand their knowledge and creativity by innovating new technologies application for Engineering Education is currently under way to engage the university and the community. Concluding, Mr. Lugo's ambition is to encourage students to focus in science, technology and engineer abilities in order to expand their professional potential.

\section{Mr. Mike Thomas Pitcher, University of Texas, El Paso}

Mike Pitcher is the Director of Academic Technologies at the University of Texas at El Paso. He has had experience in learning in both a traditional university program as well as the new online learning model, which he utilizes in his current position consulting with faculty about the design of new learning experiences. His experience in technology and teaching started in 1993 as a student lab technician and has continued to expand and grow over the years, both technically as well as pedagogically. Currently he works in one of the most technically outstanding buildings in the region where he provides support to students, faculty, and staff in implementing technology inside and outside the classroom, researching new engineering education strategies as well as the technologies to support the 21st century classroom (online and face to face). He also has assisted both the campus as well as the local community in developing technology programs that highlight student skills development in ways that engage and attract individuals towards STEAM and STEM fields by showcasing how those skills impact the current project in real-world ways that people can understand and be involved in. As part of a university that is focused on supporting the 21 st century student demographic he continues to innovate and research on how we can design new methods of learning to educate both our students and communities on how STEM and STEAM make up a large part of that vision and our future.

\section{Mr. Hugo Gomez, University of Texas, El Paso}

Mr. Hugo Gomez works as an Instructional Technologist at the University of Texas at El Paso, he is focused on expanding the professional and technical skill sets of our students and faculty community to better prepare them for the world of technology today and tomorrow. He works alongside a wide assortment of students, faculty and staff on campus to make sure their technology toolsets are up to date. Furthermore, Hugo provides workshops to over half of the student population at UTEP and as such, has been instrumental in providing the behind the scenes support to all these courses. Mr. Gomez also collaborates in the Learning Lab team to explore and implement new educational strategies in the classroom. Mr. Gomez has a Masters Degree in Engineering Education from The University of Texas at El Paso. He has participated in the UTEACH summer program as a Technology Instructor in which he provided workshops on website design, movie creation and computer networking. In addition, Mr. Gomez teaches UNIV1301 Foundations of Engineering, were students learn academic, personal and engineering skills, among many other abilities that help them understand their opportunities and responsibilities as engineering students.

\section{Dr. Oscar Antonio Perez, University of Texas, El Paso}

Mr. Oscar Perez received his PhD. in Electrical Engineering from the University of Texas at El Paso (UTEP) with a special focus on control systems and data communications. He was Awarded the Woody Everett award from the American Society for engineering education August 2011 for the research on the impact of mobile devices in the classroom. Dr. Perez has been teaching the Basic Engineering (BE) - BE 
1301 course for over 9 years. Lead the design for the development of the new Basic Engineering course (now UNIV 1301) for engineering at UTEP for the Engineering, Science and University Colleges. Developed over 5 new courses, including UTEP technology \& society core curriculum classes specifically for incoming freshman with a STEM background. Dr. Perez was awarded the 2014 "University of Texas at El Paso award for Outstanding Teaching". Dr. Perez has thirteen years of professional experience working as an Electrical and Computer Engineer. leads a team to provide technical support to faculty and students utilizing UGLC classrooms and auditoriums. Dr. Perez is committed to the highest level of service to provide an exceptional experience to all of the UGLC guests. Dr. Perez strongly believes that by providing exceptional customer service that UGLC patrons will return to make use of the various services the university offers. Mr. Perez enjoys working on the professional development of the students' employees at the UGLC. He shares with his student employees his practical experience in using electrical engineering concepts and computer technologies to help in everyday real-world applications. Dr. Perez has worked with the uTeach and Tech-e camp programs at UTEP since their creation to streamline the transition process for engineering students from local area K-12 schools to college by equipping students and their teachers with teaching strategies and technologies each summer. Oscar enjoys teamwork, believes in education as a process for achieving life-long learning rather than as a purely academic pursuit. He currently works on maintaining, upgrading and designing the new classroom of the future model at UTEP. Dr. Perez is inspired because he enjoys working with people and technology in the same environment.

\section{Mr. Pedro Arturo Espinoza, University of Texas, El Paso}

Pedro worked in the manufacturing industry as a Quality Control Engineer for some years before acquiring his current position as an Instructional Technologist at the University of Texas at El Paso (UTEP). For over 11 years in this role, he has worked with a team of managers that oversee various learning environments for the Academic Technologies Department at UTEP. He leads a group of more than 30 multidisciplinary student employees that help support a wide range of technologies for classrooms and other learning spaces, including videoconferencing rooms. In addition to teaching a Foundations of Engineering course, Pedro also provides technology training on Mac OS X, CISCO networking and various other technology topics. He also enjoys the role of social media coordinator for Academic Technologies to showcase the department's services and the dedicated students and staff members who work there. Pedro received his Bachelor of Science degree in Electrical Engineering and a Master of Science in Engineering with a concentration in Engineering Education from UTEP.

\section{Mr. Randy Hazael Anaya, University of Texas, El Paso}

Randy Anaya, Instructional Technologist at the University of Texas at El Paso. Received a BFA in Graphic Design with a minor in Multimedia design from the Universidad Autónoma de Ciudad Juarez, Mexico. Received a BA in Media Advertising at UTEP and is currently enrolled as a Master of Interdisciplinary Studies with an emphasis on the use of art and technology in teaching and learning. Randy works on research and development of applying the creative process to workshops, trainings and student engagement. Currently doing extensive research and deployment of emerging technologies to redefine the classroom, mentoring and excellence through student interaction.

\section{Mrs. Herminia Hemmitt, University of Texas, El Paso}

Mrs. Herminia Hemmitt is part of the Learning Environments team in Academic Technologies at The University of Texas at El Paso. She is responsible for coordinating classroom technology upgrades and implementations to ensure project deadlines and anticipated goals are met. Her educational background in organizational and corporate communication is utilized in consultations with faculty and staff about their learning environments in order to correctly match them to appropriate learning spaces or adapt existing spaces to meet their pedagogical and technological needs. Her focus is on the specific user to make sure that classroom needs, technical needs, and/or event needs are met.

\section{Dr. Peter Golding, University of Texas, EI Paso}

Professor in the Department of Engineering and Leadership at UTEP. 


\title{
Year Two, Setting Up the Right Path: 3D Printing for Low Expense College Courses
}

\begin{abstract}
:
3D printing is progressively impacting many areas of our society. While the general public is becoming increasingly aware of the possible applications of 3D printing and companies are looking to incorporate the technology, higher education's dissemination of this technology is not progressing at the same speed between various colleges within the same university. College students do have access to this new technology but at different rates, thus creating a barrier between students and their access to this trending technology. (Name Removed) will focus on the student population that may be challenged with low opportunity or no experience with 3D design and print. Having none or limited proficiency on building high technical skills could provoke challenges for research and internship opportunities. In addition, it could also slow the process of discovering groundbreaking research due to prioritizing and giving a huge amount of time in training and tutoring, instead of students already have developed and gained experience on those practical skills. The vision is to incorporate a set of guidelines that can be taken into consideration in order to ease the transition from an inexperienced student into a high-end proficient student that would not need huge time investment on teaching. In addition, an infrastructure model will be shown with capabilities to scale up/expand and adapt to each college needs without restructuring everything all over again.
\end{abstract}

\section{INTRODUCTION:}

The earliest 3D printing technology was developed in the late 1980's and was referred to as rapid prototyping technology. The idea of rapid prototyping came to be from the need for quicker and cost-efficient design testing for product development within the manufacturing industry. It wasn't until 2009, however, that 3D printers became commercially available. By 2012 several $3 \mathrm{D}$ printer companies began to offer their products on the market either as an open or licensed source [1].

3D printing is also commonly known as additive manufacturing. There are couple of processing methods for 3D printing, the printers that we currently are using would be Fused Deposition Material, trademarked by Stratasys (FDM); also commonly known as Fused Filament Fabrication, by RepRap (FFF). It consists of extruding thin layers of melted material, mostly plastic, onto a level building plate, across the length and width of the space ( $\mathrm{x}$ and $\mathrm{y}$ axis). As the thin layer is introduced through both axes, it will rise to the predetermined height selected and then repeat and start again to introduce the next layer of material across both axes.

3D printing in higher education has been available for quite some time. However, access has been limited to students at colleges across our campus. As an example to illustrate this point, only mechanical engineering students are allowed to use 3D printers located only within the college of engineering. In addition, these printers may only be available to specific classes or research groups and during very limited scheduled times. Even those students that have the opportunity to use the printers may be restricted to using them once per semester. If printers are to go offline due to failure or for maintenance, this schedule is further restricted. After a semester of collecting 
feedback from students at (Name Removed) the following was found: print queues are usually long, there is no chance for trial and error, it takes time to print the models successfully and requires constant or full-time supervision. These long queues negatively impact completion of prototypes and class projects by assigned strict deadlines. Designing a higher education open 3D lab for use by students, faculty and staff on a campus-wide level, presents many challenges due to the fact that there are hundreds of variables that could potentially hinder the lab's usefulness for so many users.

There is a growing demand for teaching concepts enhanced by the use of 3D printing. There are some schools that have bought several printers and new methodologies and pedagogies are being incorporated to address the unique application of 3D printing in the classroom. In general, instructors lecture on certain concepts and theories and a 3D printer is used to create final a model that is used to further aid in the explanation of the material covered [2]. The goal of this research is to pilot a campus-wide 3D printing system along with the space where students will be able to work on 3D designs and projects and have the opportunity to supervise the printing of their own prototypes. An additional goal is to provide instructors with a vehicle that will allow them to assign and/or demonstrate more in-depth details of the material being covered with the expectation that the implementation of this technology and associated pedagogies may lead students to realworld solutions. Students that have registered into our pilot program have the opportunity to design, innovate and create 3D models that could aid them in their degree, courses and/or personal skills without being required to belong to a specific degree.

\section{RESOLUTION:}

(Name Removed) is constantly developing on the design of a 3D printing open lab. This effort started in mid November 2015 and several procedures have been developed and constantly been changing based on the data that has been collected for the first year of the pilot program. Currently, different 3D model submissions are continuously being tested and (Name removed) are able to determine how to implement the best methods and techniques for such vision. Based on previous students, faculty and staff feedback, this modified system should allow with the aid of (Name removed); a supervision of 3D printing models via a website using webcams, predetermine and experiment print setting parameters in order to increase quality, speed and efficiency in their final models. In addition, students should be able to print their own design using standard or alternative plastic materials with specific attributes such as flexibility, transparency, electrical conductivity, magnetic or any other material that is compatible with the printer. Of utmost importance, this model has to be able to be escalated to a campus-wide system to allow access to the entire student body. (Name Removed) has created the first and basic 3M's checklist that must be considered and of course suggested before thinking about adopting a 3D Printing Lab. In addition, our research has shown the specific parameters that must be taken into consideration for a charging system that could sustain and return on investment by not limiting and overkilling the enthusiasm and price of $3 \mathrm{D}$ printing for students at any degree.

\section{METHOD AND DEISGN:}


Courses at a college level could be challenging compared to a regular year grade. The extensive and demanding content that must be taught within less than a semester definitely impacts on the student development. On a $21^{\text {st }}$ century demographic era, instructors must cover and enforce different stages through out their content. Such stages could consist into four parts; Discovery Learning, Opportunity, Hands on and Analytical Thinking.

1) Discovery Learning can be known, as the introductory phase. The subject introduction must be taught properly, well grounded, the fundamental concepts must be well understood and within a reasonable small amount of time, one or two weeks.

2) Opportunity is the period on which the student can expand the knowledge, explore new and unique methods, design and finally begin to execute in order to reach from a concept to tangible. This stage would take more time than the previous one.

3) The Hands on segment is the most critical and the one that takes the longest time. This is where the student gets to be contested, the constant process of trial and error; this is where the student gets to transform an idea to reality.

4) Finally, "Analytical Thinking" could be called as the ethereal section. There will always be a need for improvements, a perception that something could be modified in order to enhance and look flawless your final project/product

The opportunity of having a maker space available or 3D print lab near you, with innovative and capable features and unique skills; it could set you into a higher advantage situation with potential skills trending at the market. The limited time during class and possibly running into not having the correct equipment for 3D design and print, it could narrow the motivation to explore different pedagogies and techniques for your course. Probably there could be no better methodology than to stimulate the interest on the student to overcome and think ahead. Student driven projects should be emphasize in order to let the students develop an intrinsic motivation for learning outside the class.

A maker mindset can be classified as a "creative problem solving, acquainting technical engineering skills". Accordingly to Jennifer Pocock in Maker Movement 2.0, she states, "You can not have engineering without analysis" [3]. The most critical points that should be accounted for are: Don't focus on the perfect final product. Students are able to: brainstorm, acquire CAD skills, 3D design, 3D print, Prototype, Assembly, Viable Test, Product Quality, provide constructive feedback, differentiate product needs, analyze to redesign and reiterate their model. A maker space is a physical location where people could gather up and share resources knowledge, construct, network and work on projects where you are not limited to experience at least:

- Create/Design

- Expand your interest

- Develop critical thinking

- Craft Engineer / Art Inventor

- Interact/ Own pace environment

- Enhance Technology 
- Student Driven Projects

- Hands on

- No restraint on improving a concept

- Open mindset

- Collaborate

A question may rise on how could it be possible a low-budget place be able to sustain and deploy an expensive technology enhancement. The first stage in being able to deploy/scale up is critical and should be consider in order to be effective. The following suggest guidelines could ease the uncertainty; it can be call as the 3M's (Model, Method and Material).

1. - Models: The first phase comes into play by asking certain subsections such as: scope of demand and resources/expenses. The most important objective is to determine the population, demand, how to plan and set a proper structure and the ability to scale up without vast issues. There must be a mindset by having a realistic and guaranteed budget for your project, do not only take in consideration the price of the printer and thinking the highest number of printers you can get but also the cost of having trained personnel; people who will oversee the printers, troubleshoot/maintain properly the printers, give proper and qualified workshop for 3D design and print. Price can decrease drastically if the designer, the student, will oversee his/her own model. Especially if the print model takes more than ten hours or even days! Like previously said, there's must be a predefined structure, the following diagram will explain some of the key aspects that must be taken into account for setting a proper structure, it can be mix and modified to the needs that will satisfy your model:

Expensive

A)Hire: Professional people who will setup the lab, oversee designs, print models, troubleshoot printers, provide workshops in 3D design and print, refine printed objects.

B) Send print models to online or local companies that offer the service of 3D printing.

(B section would only be low-cost on a short-term period, only recommended for one pilot semester class)

C) Hire: Professional people who will setup the lab, person who will oversee designs, provide workshops in 3D design and print. Makers will oversee and refine their own print models.

D) Fee Training: How to oversee designs, print models, troubleshoot printers, provide workshops in 3D design and print, refine printed objects. Makers will oversee and refine their own print models.

(WARNING: Least recommended, number five)

E) If you have the time, access, money and opportunity to tweak and learn by yourself about 3D design and print, gain knowledge and experience troubleshooting by 
online blogs, articles and videos which are accessible now a days and easy to follow step by step. The best experience for a passionate person is by try and error.

Low-cost

2. - Methods: This is a critical fragment on which the instructors would play a huge role. The instructors would have to pre-assemble the syllabus with projects, activities and topics that could integrate 3D design and print. Based on the model structure, there are two possible types of scenarios:

A) Local: If there's a limited number of printers and classes, then you would have two options. First, basic printers that support 2.0 USB, SD card slot and/or USB type A, on which you would have to manually select the print file you would like to start. The second would be printers with wireless connectivity and embedded camera that can monitor the print and be controlled through the internal Wi-Fi network.

B) Offsite: If there's a large number of printers and classes, then it would be suggested to go through a different path. 3D printing online systems consist of creating a network of 3D printers with raspberry pi Wi-Fi enable or Ethernet port and a web cam. The big advantage of this solution is that it can be managed through the Internet and monitor the print. There are two types of accounts for this system: user and administrator. As a user, one is able to upload stereolithography files (common 3D printing file extension), search for sharable and public prototypes, complete simple edits on your model, share files between registered users, fix and slice the .stl (stereolithography) file and finally send it to the print queue. As an administrator, one can manage the models being sent to print by selecting which ones are permitted to print and on what printer from the available ones on the network. One can also restart printing if it fails without sending it again, cancel the print, create access groups, manage the printers, generate types of reports such as the number of accounts and printers with number of prints, print errors, material used, total print time, billing and many more features.

3. - Materials: Research must be done before selecting the printers in order to maximize printer usage and diversity material selection. As students gain expertise on 3D printing, several of them might start to ask about different materials that can be used to create their 3D printed models with different attributes. When selecting printers, you must take into consideration that different brand of filaments only manage specific/both filament size $(1.75 \mathrm{~mm}$ or $3 \mathrm{~mm})$. Another vital factor is whether it has heated bed or not, this reduces the usage of disposable material such as Kapton and/or blue tape (aids the adhesion between the print object and build plate). Different materials such as: Acrylonitrile Butadiene Styrene (ABS), Polylactic Acid (PLA), High Impact Polystyrene (HIPS), Nylon, Polyethylene Terephthalate (PET), Polyvinyl Alcohol (PVA), carbon fiber, wood, bronze, copper, glowfill, conductive, magnetic and many more filaments can be found in now a days on the market. Not all of our needs were fulfill on our first year such as auto-level and multiple extruders but our main criteria was:

- Low budget, therefore we looked for low cost printers less than three thousand

- Good reasonable dimension build plate

- Heated bed platform 
- Incredible layer resolution

- Option to upgrade an extra extruder

- Auto-leveling

- Print Speed (depends if it's just for prototyping or finalize model)

- Good Reviews

\section{FIRST YEAR:}

A proposal was submitted in order to purchase multiple printers to continue the pilot. The first rule that applies to any kind of facility is safety. 3D printers emit ultrafine particles (UFP) and volatile organic compounds (VOC), which could lead to health effects. Out of all the available materials, PLA is one of the lowest emission rate materials and ABS is one of the highest ones that emit large UFP. It is suggested to plan accordingly with a design and deploy of ventilation systems and the best use of air filters. As mentioned before on the introduction, FDM has the capability to print on both materials. Based on the research made, a couple of printers were filtered based on our necessities; it was opted for PLA printing. After our experiences with the first two Makerbot models, we concluded that the new printers must have: 1) less issues with clogging, 2) provide high quality printed models with fine layer resolution, 3) contain a heated platform for printing different type of materials and use less consumable materials such as blue tape, 4) have the ability to upgrade extruders, and 5) provide auto leveling of the bed. Figure 1 depicts a list of printers that were considered based on our requirements. 3D printing is still under development in terms of reliable slicing, method of transferring a 3D model into a physical device such as USB, SD card or wireless through the cloud. There are companies nowadays that have substantially raise the bar in terms of precise auto level, increase the number of print heads to at least two, integrate a camera within the printer, send the print model through the WiFi network and lastly reduce the cost of price as it was some years ago.

While our research for printers was being completed, a new partnership was made with [name removed]. This new piece of software provided a central management portal for all design files for $3 \mathrm{D}$ printing via a cloud-based platform. This online printing system consisted of a network of printers (a list of compatible printers was provided), a raspberry pi with Wi-Fi enable or Ethernet port, a web cam, a 1- year unlimited license, on-site deployment, training and support. The big advantage of this solution is that the printers can be installed within a network and be managed through the Internet.

There are two types of accounts for this system: user and administrator. As a user, one is able to upload stl files (common 3D printing file extension), search for sharable and public prototypes, complete simple edits on your model, share files between registered users, fix and slice the stl file and finally sent file to the print queue. As an administrator, one can manage the models being sent to print by selecting which ones are permitted to print and on what printer from the available ones on the network. One can also restart printing if it fails without sending it again, cancel the print, create access groups, manage the printers, generate types of reports such as the number of accounts and printers with number of prints, print errors, material used, total print time, billing and many more features. 
In conclusion for our first year, we selected four Ultimaker 2 from all the other eight possible options because it met most of our needs such as less than 3,000 dollars, the print size dimension met our needs, layer resolution was exceptional than most of all printers at that time, heated build platform was extraordinary and there was a possibility for upgrading to a dual extruder. The [name removed] strongly suggested at that time, dual extruder was not fully optimized because the software was not stable and there was a lot of research on such subject.

\begin{tabular}{|c|c|c|c|c|c|c|c|c|c|c|}
\hline Rating & \begin{tabular}{|l} 
Filam \\
ent \\
Size \\
\end{tabular} & Name & Price & \begin{tabular}{|l} 
Quality \\
Score
\end{tabular} & Dimension & $\begin{array}{l}\text { Layer } \\
\text { Resolution }\end{array}$ & $\begin{array}{l}\text { Print } \\
\text { Speed } \\
(\mathrm{mm} / \mathrm{s})\end{array}$ & $\begin{array}{l}\text { Heated } \\
\text { Platform }\end{array}$ & $\begin{array}{l}\text { Dual or Triple } \\
\text { Upgradable Heads }\end{array}$ & $\begin{array}{l}\text { Auto- } \\
\text { leveling }\end{array}$ \\
\hline 1 & $3 \mathrm{~mm}$ & $\begin{array}{l}\text { Ultimaker } \\
2 \text { Extended }\end{array}$ & 3,030 & $95 \%$ & $9.0 " \mathrm{x} 8.8 " \mathrm{x} 12^{\prime \prime}$ & $\begin{array}{l}0.02- \\
0.2 \mathrm{~mm} \\
\end{array}$ & $30-300$ & Yes & & No \\
\hline 2 & $3 \mathrm{~mm}$ & $\begin{array}{l}\text { Ultimaker } \\
2\end{array}$ & 2,500 & $95 \%$ & $8 " \times 8.8 " \times 9 "$ & $\begin{array}{l}0.02- \\
0.2 \mathrm{~mm} \\
\end{array}$ & $30-300$ & Yes & $\begin{array}{l}\text { Optional (not } \\
\text { recommended) }\end{array}$ & No \\
\hline 3 & $3 \mathrm{~mm}$ & $\begin{array}{l}\text { Lulzbot } \\
\text { Taz } 5 \\
\end{array}$ & 2,300 & $85 \%$ & $9.8 " x 10.8 " x 11.7 "$ & $\begin{array}{l}0.075- \\
0.35 \mathrm{~mm}\end{array}$ & 200 & Yes & 2 & No \\
\hline 4 & $3 \mathrm{~mm}$ & $\begin{array}{l}\text { AirWolf } \\
\text { (Axiom) }\end{array}$ & 4,000 & $85 \%$ & $12.5 " \mathrm{x} 8$ "x $10 "$ & & 250 & & & Yes \\
\hline 5 & $\begin{array}{l}1.75 \mathrm{~m} \\
\mathrm{~m}\end{array}$ & $\begin{array}{l}\text { Cubify } \\
\text { Cubepro }\end{array}$ & 2,800 & $95 \%$ & $\begin{array}{l}7.8- \\
11.2 " \mathrm{n} 10.5 " \mathrm{n} 9 "\end{array}$ & $\begin{array}{l}0.07- \\
0.3 \mathrm{~mm}\end{array}$ & 15 & & 3 & Yes \\
\hline 6 & $3 \mathrm{~mm}$ & $\begin{array}{l}\text { AirWolf } \\
(\mathrm{HD} 2 \mathrm{x})\end{array}$ & 4,000 & $85 \%$ & 11 "x8"x12" & & 150 & & Yes & No \\
\hline 7 & $3 \mathrm{~mm}$ & $\begin{array}{l}\text { AirWolf } \\
(3 \mathrm{D} \text { HD) }\end{array}$ & 3,000 & $85 \%$ & $12 " x 8 " x 12 "$ & $.06 \mathrm{~mm}$ & 150 & Yes & & No \\
\hline 8 & $\begin{array}{l}1.75 \mathrm{~m} \\
\mathrm{~m}\end{array}$ & Makerbot & 2,900 & $85 \%$ & $5.9 " x 7.8 " x 9.9 "$ & $.1 \mathrm{~mm}$ & Various & & & No \\
\hline 9 & $\begin{array}{l}1.75 \mathrm{~m} \\
\mathrm{~m}\end{array}$ & $\begin{array}{l}\text { Makerbot } \\
\text { Mini } \\
\text { Replicators }\end{array}$ & 1,400 & $80 \%$ & $4.9 " x 3.9 " x 3.9 "$ & $.2 \mathrm{~mm}$ & Various & & & No \\
\hline
\end{tabular}

Figure 1. Ranking of printers based on our requirements (Nov 2015)

\section{SECOND YEAR:}

If you have a system that works perfectly fine without many issues, easy to troubleshoot, great costumer service and every year the company keeps upgrading the product, then there is no real reason to completely change the whole subsystem. Another set of four printers was purchased for our second year. Three out of the four printers was based with our experience with Ultimaker, the decision was Ultimaker 3 because it includes dual extruder, auto level build plate, integrated camera, easy attach and detach printheads, better resolution than other well known printers, Wifi and Smartphone App Capability for wireless printing, recognize material that your are using on each printhead and USB capability. The other printer that was selected is the Form 2 due to the fact that there was a high demand for better resolution on the prints, explore new materials for patents and research and develop new skills with different type of printers, in this case Stereolithography, SLA. The factors that contributed to continue mainly with Ultimaker printers besides the new product enhancements are:

1) Printed 2,784 3D models with four printers within a year 
2) Average of 696 prints in a year per printer

3) Biggest issue was to replace one board, the printers come with one year warranty parts

4) Consumable items that had to be replace due to huge amount of prints were: nozzles $0.4 \mathrm{~mm}$ (every three to four months), PTFE isolator coupler (every six months), heater cartridge (every six months) and PT100B printhead temperature sensor (six months)

So in a year, the total cost for running a 3D pilot program was less than forty-three thousand dollars. The budget was split into four segments:

a) Five part time students to cover 3D design, print, third party software Workshops and manage/supervise $3 \mathrm{~d}$ models before being to sent for the whole year. 35,625 dollars

b) Third party license software for central management via a cloud-based platform. 3,600 dollars

c) Materials: Sixty-four Kilograms of PLA filament. 2,560 dollars

d) Consumable materials: 48 Nozzles, 8 PTFE, heater cartridge and PT100B. 1,160 dollars

\begin{tabular}{|c|c|c|c|c|c|c|c|c|c|c|}
\hline Rating & $\begin{array}{l}\text { Filament Size } \\
\text { and material } \\
\text { capability }\end{array}$ & Name & Price & Type & Build Plate & $\begin{array}{l}\text { Layer } \\
\text { Resolution }\end{array}$ & $\begin{array}{l}\text { Print Speed } \\
(\mathrm{mm} / \mathrm{s})\end{array}$ & $\begin{array}{l}\text { Heated } \\
\text { Platform }\end{array}$ & $\begin{array}{l}\text { Dual } \\
\text { Extruder }\end{array}$ & $\begin{array}{l}\text { Auto- } \\
\text { leveling }\end{array}$ \\
\hline 1 & $\begin{array}{l}\text { 3mm PLA, PVA, } \\
\text { CBS, CPE, Nylon }\end{array}$ & $\begin{array}{l}\text { Ultimaker } \\
3 \text { Extended }\end{array}$ & 4,300 & FDM & $\begin{array}{l}215 \mathrm{~mm} \mathrm{X} \\
215 \mathrm{~mm} \mathrm{X} \\
300 \mathrm{~mm}\end{array}$ & $\begin{array}{l}0.02- \\
0.2 \mathrm{~mm}\end{array}$ & $30-200$ & Yes & Yes & Yes \\
\hline 2 & $\begin{array}{l}3 \mathrm{~mm} \text { PLA, PVA, } \\
\text { CBS, CPE, Nylon }\end{array}$ & $\begin{array}{l}\text { Ultimaker } \\
3\end{array}$ & 3,500 & FDM & $\begin{array}{l}215 \mathrm{~mm} \mathrm{X} \\
215 \mathrm{~mm} \mathrm{X} \\
200 \mathrm{~mm}\end{array}$ & $\begin{array}{l}0.02- \\
0.2 \mathrm{~mm}\end{array}$ & $30-300$ & Yes & Yes & Yes \\
\hline 3 & Resin & Form 2 & 2,300 & SLA & $\begin{array}{l}145 \mathrm{~mm} \mathrm{X} \\
145 \mathrm{~mm} \mathrm{X} \\
175 \mathrm{~mm}\end{array}$ & $\begin{array}{l}.025- \\
.1 \mathrm{~mm}\end{array}$ & 200 & \begin{tabular}{|l|} 
Self- \\
heating \\
resin \\
tank
\end{tabular} & & \\
\hline 4 & $\begin{array}{l}\text { 1.75mm PLA, } \\
\text { ABS, PET, HIPS, } \\
\text { PVA }\end{array}$ & $\begin{array}{l}\text { Lulzbot } \mathrm{Ta} z \\
6\end{array}$ & 3,000 & FDM & $\begin{array}{l}280 \mathrm{~mm} \mathrm{X} \\
280 \mathrm{~mm} \mathrm{X} \\
250 \mathrm{~mm}\end{array}$ & $\begin{array}{l}0.05- \\
0.5 \mathrm{~mm}\end{array}$ & 200 & Yes & Yes & Yes \\
\hline 5 & $\begin{array}{l}\text { 1.75mm PLA, } \\
\text { ABS, PET, HIPS }\end{array}$ & $\begin{array}{l}\text { Makergear } \\
\text { M2 }\end{array}$ & 2,225 & FFF & $\begin{array}{l}200 \mathrm{~mm} \mathrm{X} \\
250 \mathrm{~mm} \mathrm{X} \\
200 \mathrm{~mm}\end{array}$ & $\mid \begin{array}{l}.05-.25 \\
\mathrm{~mm}\end{array}$ & $80-200$ & Yes & Yes & \\
\hline
\end{tabular}

Figure 2. Ranking of printers based on our requirements (Nov 2016)

\section{COLLABORATION:}

After determining the correct structure that your organization may need, the next step would be the interaction between Faculty, Staff and Student members. Being able to collaborate and understand each other needs, reach/set realistic goals and be able to execute precisely, will definitely determine the success of the program and students' learning outcomes. The following recommendations for college course integration would mainly consist on incorporating a preexisting syllabus project with 3D design and print capability. 
In the perspective of a Faculty member; the utmost important point that will define if the course could succeed is:

- Create and establish a 3D project that could exploit and encourage your students into a challenging phase related with a topic of your course.

- Identify and set the complexity of the project, establish project timeline, project expectation and how many people should be set per team or be an individual assignment.

- Pre arrange a workshop specialist for 3D design and print

- Have constructive feedback sessions and if possible a STEAM qualified competition for best model

In the perspective of a Staff member; these are the questions that should be taken accounted:

- The designs would have to be uploaded through a system. Locally or Offsite as mention before in the $3 \mathrm{M}$ 's

- The stl files must be saved under a strict format for managing purposes: Course name-(name of the instructor)-(name of the team/person)

- Identify the maximum print dimensions the printer can handle. For Course purposes: set a limit on the print size, it is not recommend to print at maximum print

o Strongly do not recommend to print multiple objects in one single stl file since it may increase the rate of failure print

- Maximum dimensions will take more than $24 \mathrm{hrs}$ to print, therefore it will increase the error rate, use large quantity material and possibly ran out of filament while being print overnight.

- Based on the number and complexity of prints per class, try to make a friendly two weeks timeframe anticipating all the worst possible scenarios, troubleshooting and sending back and forth emails to students for the best print method in order to have all the prints ready and be turned in on time

- Enforce a 2-phase stage:

○ Small object prototype (During the first half semester). This will aid students to get a perspective of dimensions and make some final changes for their final print (Students definitely want to make some final changes in their product before submitting)

- Final product (at the end of the semester)

Faculty with Student - Staff with Student Interaction:

- The most important aspect in any education dissemination level is the student. We are entitled as an adult to show the correct path every student should take, in order to expand his skills and encourage his/her will of learning, making and executing. Student demographic can be split into two sections at higher education: students that are taking the course and students that work as part-time job. Communication between Faculty and Students should always have a constant feedback. It adds a great value when there is an interaction by sharing information of what does really works and what needs to be improved throughout the semester. This way the next semester the professor could modify and make the project better and more challenging according to the students' feedback. The interaction between Staff with students is considered as the assessment and assignment of managing the printers. The staff must know from front to end how the printers work, tutor the students that will aid in overseeing/troubleshooting the print models. The staff should be able to educate the part-time students how to provide one to 
one or a huge class of students, the proper workshop for 3D designing and printing. The parttime students should develop soft skills such as replying emails with proper feedback on how could the model be optimized for 3D printing and professionally answer students' question in $3 \mathrm{D}$ designing and printing.

\section{CHARGE SYSTEM:}

"If you want 3D printing you have to have capital and understand it; you can't buy it as a service in a straight forward way" [4]. Having the right amount of resources and the proper trained personnel, it is a critical key point to implement and design a new 3D open lab printer structure without any bumps along the road. Creating a 3D print charge system and forecasting the usage of filament per printer in a week daily basis under regular and overkill usage could make it a nightmare. Still under work of creating the most reliable print system; critical parameters, from lowest to highest, are arranged and accounted for a print charge system can be classified as the next 3 subsets. Some parameters that are included affect mainly the total object weight and total print time, such as infill percentage, layer height and print speed.

\section{Subset Parameters}

A. Weight Parameters: Total Object Weight, include support and platform adhesion (1), Infill $\%(7)$

B. Time Parameters: Price per Hour (3), Total Print Time Hours (4), Layer Height (5), Print Speed (8)

C. Miscellaneous Parameters: Filament Cost (2), Workforce / Supervising (6), Failure Rate (9), Repair Costs (10), Disposable Material Cost (11) and Electricity (13)

The most important parameters based on our criteria are the Total Weight, Total Print Time and Print Time Charge per Hour. The substantial parameter that will determine how much it could increase the price is Print Time Charge per Hour. Under the row "Our Service", refer to Figure 1; there is a comparison with only charging the total weight versus adding an extra charge of Print Time Price per Hour. It shows how much it could increase by just adding 50 cents per hour up to a $264 \%$ increase in total price. With only taking these three main parameters, it could possibly cover basically all the other parameters such as failure rate, repair costs, disposable material cost and electricity. The questions that have arose are: could it cover completely or partially the workforce / supervising parameter and should it even be consider to cover such element? Most of the high prestige colleges charge 2 dlls per Hour or does not charge at all due to the high college tuition. 


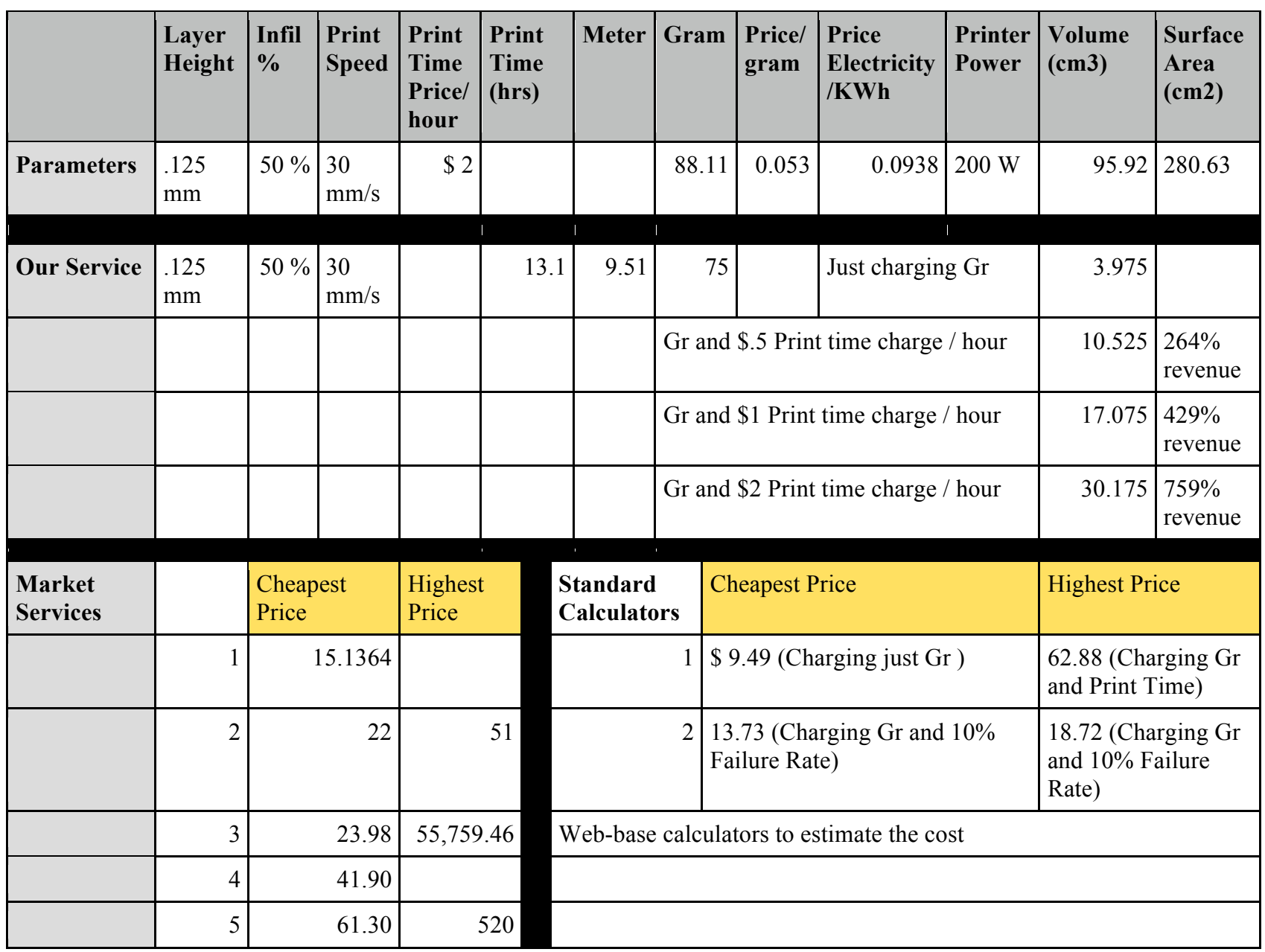

Figure 3. Print Charge System.

\section{CONCLUSION:}

The long-term goal of this research is to measure the benefit of a 3D printing open lab for students at (Name removed). The privilege of being part of a pilot program should not be made available solely to freshmen students in an introductory engineering course. This kind of program should always be open to any student in any discipline from liberal arts, nursing, computer science, business, as well as engineering. As such, an open-lab concept was created as a pilot where students from any discipline could print for free. This allows students the ability to start thinking about what 3D printing is, and make connections as to how they can use this for the education and personal skill development.

The vision of this project is to provide enough resources to all students on which they could implement 3D printing for assignments to be used in all their courses. Our research intent is to open doors and start the discussions among faculty on how to incorporate this new technology in their classroom. For example, students could struggle on their senior project design thinking on using metal or wood, which could be expensive, compared to plastic as prototype. Having the opportunity to modify parameters and reprint in terms of hours could bring a substantial 
improvement on time management, cost savings and with different material properties. This development can potentially assist instructors in reinforcing concepts into applied examples and create huge impacts on student learning.

3D design and print technology is in a fast pace and competitive phase, there are hundreds of 3D printers available on the market and each of them potentially satisfies a specific or multiple needs. Each year the market offers new enhancements, but the requirements of every entity scales up at higher rate and sometimes differs between each entity. It is hard and unique to find a product that could globally fulfill everyone's demand. This is why it is critical to think and plan thoroughly in the design and deploy of a 3D printing lab using as a base guideline the 3M's. For low expense college budget, the part time student workforce takes eighty-two percent of the total budget for 3D printing lab facility. The printers, third party license software's, filaments and disposable items could be easily sustained by the print charge system.

By changing one variable on the 3D print charge system, the Print per Hour. Any school, business or university can determine how much additional contribution can be incorporated on the capital recovery. Generating this revenue, it can sustain total cost for repairs, compensate partial failure rate on 3D models, disposable material costs, additional critical spare parts for inventory, increase the number of workforce and supervision, restock filament and generate new capital for more available 3D printers or buy a specific high end 3D printers. As you increase the print per hour it could not disrupt students monetarily on small time print, but it could remarkably affect on longer time prints and discourage students. Therefore, there is a limit on how much you could charge print per hour.

\section{FUTURE WORK:}

The future scope of work is to continue researching how to optimize a campus-wide 3D open lab at low cost and the ramifications of unrestricted printing. Should it truly be open to whatever a student wants to print? Should rules for printing items such as a 3D weapons be enforced? In addition, solid numbers on the needs of each college in terms of quantity of printers, different brands and types of printers, different types of materials, and printing limits per student based on classification, number of credits, or degree need to be addressed. Feedback on possible friendlier user-interfaces, faster model rendering, precise slicing software, intuitive print queue systems with new features that could expedite or improve printing must still be gathered and provided to manufacturers.

We are looking to research, test, implement and deploy laser cutter and computer numerical control CNC machines. "There is no 'best' 3D modeling software. The choice of 3D modeling software however is rather large. There is specific software for a myriad of disciplines like architecture, sculpting, animation, engineering, product design and jewelry design. With each software there are also various price points for licensing; how much money can be allocated to spend on 3D modeling software, which ranges from free to a few thousand dollars" [5]. And to that end, we will also develop more workshops with distinctive software that could potentially increase student's proficiencies in 3D design for any kind of degree. Instructors that want to incorporate 3D design into their course must have already done background research on how 3D could 
complement their course content and create design activities that could reinforce the concepts. Finally, we are researching on how to provide a set of guidelines for Build Your Own (BYO) 3D Printers.

\section{REFERENCES:}

[1] Anon, “3D Printing History: The Free Beginner's Guide - 3D Printing Industry," https://3dprintingindustry.com/3d-printing-basics-free-beginners-guide/history/, (accessed January 2016).

[2] MakerBot Education, MakerBot in the Classroom: An Introduction to 3D Printing and Design, Independent Publisher, 2015.

[3] J. Pocock, “Maker Movement 2.0,” http://www.asee-prism.org/maker-movement-2-0/, 2016, (accessed January 2016).

[4] B. Carte, "Staples Partners with 3D Systems to Bring 3D Printing to Stores," http://www.usatoday.com/story/tech/personal/2014/04/11/staples-3d-printing/7596141/, 2014, (accessed April 2016).

[5] Anon, "Frequently Asked Questions| 3D Printing Service | i.materialise," https://i.materialise.com/faq, (accessed March 2006). 